\title{
Exploring the Factors Associated with Infant Mortality in Rural Indonesia
}

\author{
Dian Kristiani Irawaty ${ }^{1}$, Indra Elfiyan ${ }^{1} \&$ Edy Purwoko ${ }^{1}$ \\ ${ }^{1}$ Badan Kependudukan dan Keluarga Berencana Nasional, Jakarta, Indonesia \\ Correspondence: Dian Kristiani Irawaty, Badan Kependudukan dan Keluarga Berencana Nasional, Jakarta, \\ Indonesia. Tel: 62-8111807802. E-mail: dian.pusdu@gmail.com
}

Received: October 7, 2020 Accepted: November 11, 2020 Online Published: November 20, 2020

doi:10.5539/gjhs.v13n1p17 URL: https://doi.org/10.5539/gjhs.v13n1p17

\begin{abstract}
Infant mortality is a sensitive indicator to measure the health condition of a population. Despite large declines in infant mortality rates in Indonesia, the people living in rural areas are the most affected. This study aims to analyze the causes of infant mortality in rural Indonesia and suggested strategies for its reduction. This study is an analytical cross-sectional design based on the 2017 Indonesian Demographic and Health Survey (IDHS) dataset for children. The information on infant deaths collected from those mothers who experienced infant deaths. Series of logistic regression models were used to select the significant factors affecting infant mortality in rural Indonesia. Infant mortality is associated with intermediate social determinants such as birth order, birth weight, and breastfeeding status. Socio-demographic factors such as the educational status of mothers, wealth quintile, the smoking habit of the mother, age of mother at first delivery, and sex of the baby are also related to infant mortality. The most crucial factors in rural Indonesia were the age of first-time mothers. As a strategy for addressing the issue of infant mortality in rural areas, the result of the study highlights the need for decreasing adolescent pregnancies among the youngest age groups. Pregnant mothers in the youngest age group should be supported by quality maternal health services to ensure their pregnancies in healthy condition. The focus of breastfeeding promotion programs should be encouraged, particularly on early initiation and duration of breastfeeding.
\end{abstract}

Keywords: infant death, infant health, rural children

\section{Introduction}

Globally, the well-being and health status of families and communities are estimated indirectly by infant mortality. Infant mortality becomes a general indicator used for public health measurements across areas and periods (Ely et al., 2017). Sustainable Development Goals (SDGs) have set to reduce newborns deaths to at least as low as 12 per 1000 live births and under-5 mortality to at least as low as 25 per 1000 live births (United Nations, 2017; WHO, 2018). Thus, infant mortality analysis is very crucial for development planning and evaluation programs. Indonesia had experienced a further reduction in infant mortality rate from 59 deaths per thousand live births in 1988-1992 (BPS et al., 1991) to 24 deaths per thousand live births in 2015-2017 (BKKBN et al., 2018). Although some improvements made in recent years, infant mortality has not been quantified, particularly in rural Indonesia.

Further analysis indicated that relationships between socioeconomic characteristics and infant mortality were strong in rural areas than in urban areas. Earlier studies revealed that rural infants were faced with higher probabilities to experience deaths compared to urban infants (Ajaero \& Owoh, 2013; Mustafa, 2008). Higher infant mortality associated with proximate risk factors that were more common in nonmetropolitan areas, including birth order (Kynast-Wolf et al., 2019), birth weight (Chen et al., 2016), and breastfeeding status (Banerjee, 2018; Sari, 2016). Infant mortalities were more likely to be related to exogenous socio-environmental determinants, such as the educational background of the mother (Kiross et al., 2019; Santos et al., 2016); wealth quintile (Adewuyi et al., 2017; Kumar \& Singh, 2014; Mohamoud et al., 2019); smoking habits of the mother (Ratnasiri et al., 2020), age of mother at first delivery (Weldearegawi et al., 2015), and the sex of the baby (Byberg et al., 2017; Boghossian et al., 2018).

Based on earlier research, the association between birth order and infant mortality revealed a u-curve, in which both first-and later-infants had a higher probability of dying compared with those in the middle curve (Mishra et al., 2018; Modin, 2002). Mothers to first-born infants tended to be inexperienced and have fewer material resources to access health care facilities that can cause higher probabilities of infant deaths. As the number of children within a 
family increase, mothers to third or later-born infants had more likely to experience parental pressure (Ahrens et al., 2017). Those mothers who had third or later-born infants were also less likely to initiate prenatal care, consume prenatal vitamins, and breastfeed compared with their earlier-born infants (Ahrens et al., 2017). Moreover, based on the hypothesis of biological depletion, later-born infants were more likely than their elder siblings to be less healthy since those infants were born to elder mothers who had delivered to some infants before, thus, physiologically less able to have tougher infants (Riodan et al., 2011; Hotz \& Pantano, 2015).

The low-birth-weight had a greater probability of infant mortality. Infants weighing less than 2500 grams are more likely to experience visual problems due to pulmonary dysplasia (Travers et al., 2018), retinopathy of prematurity (Natarajan et al., 2019), respiratory infections (Everard, 2016), and heart illness (Hughes et al., 2017). Low birth infants have a higher probability of hospitalizations, developmental failure, and growth disorders particularly in the initial year of life (Liang et al., 2018; Vilanova et al., 2019).

Breastfeeding status is also very much associated with infant mortality. World Health Organization (WHO) suggested exclusive breastfeeding for six months continued breastfeeding up to 2 years of age to prevent children from diarrhea's (Shahid et al., 2019) and pneumonia's illness (Oktaria et al., 2017). Christian et al. (2015) had emphasized that breastmilk's nutrition is crucial for brain development, physical growth, gut maturity, preventing infection and inflammation, and promoting mother-infant attachment.

In regards to the association between socioeconomic status and infant and child mortality, Kiross et al. (2019) emphasized the effect of the educational background of the mother on decreasing infant mortality. Furthermore, Motsa et al. (2016) reveal a notion that the mother's schooling would influence the mother's knowledge of general nutrition and health care practices that might encourage those mothers to perform better health behavior and by altering the traditional marital relationships. Mother's education can increase the chance of infant survival by postponing women to marry and enter motherhood later and have fewer children, employ prenatal care, and vaccinate their children (Akter et al., 2015, Muj \& Bhradwaj, 2015).

Previous studies also showed that parents living in lower wealth index had a higher risk of infant deaths. Ladusingh et al. (2016) stated that lower households' wealth had fewer capacities to access health care, public infrastructure, clean water, nutritious food, and a safe environment than higher household's wealth. A study conducted by Roy and Haque (2018) in Bangladesh pointed out that the mothers of the wealthy family were more likely to have $45 \%$ lower probabilities of experiencing infant mortality $(\mathrm{OR}=0.55, \mathrm{CI}=0.42-0.720)$ compared to the mothers who were from the impoverished family.

The smoking habit of mothers during pregnancy is closely linked with increased risks of infant deaths. Ding et al. (2017) revealed that compared with non-smoking mothers, smoking mothers in the United States have a higher probability of infant mortality [light smoking: adjusted odds ratio $(\mathrm{aOR})=1.21,95 \%$ confidence interval $(\mathrm{CI})$, 1.03-1.43; heavy smoking: aOR $=1.30,95 \%$ CI, 1.12-1.52], correspondingly. Prenatal smoking mothers in The United States might cause short-and long-term health issues, neurologic, developmental, and neurosensory illnesses (Dietz et al., 2010).

Maternal age at first delivery is known to raise the odds of infant mortality. Kramer and Lancaster (2010) showed that young mothers faced immature physical growth that stimulates neonatal outcomes. In contrast, elder mothers had higher odds in the incidence of hypertension (Kozuki et al., 2013), gestational diabetes (Shepherd et al., 2017), and congenital abnormalities (Carolan \& Frankowska, 2011).

The sex of infants corresponded with infant mortality. A study of Humphrey et al. (2012) revealed that male fetuses are more likely to be born pre-term than female fetuses due to respiratory distress syndrome, Sudden Infant Death Syndrome (SIDS), and other infectious diseases.

Hence, this study aims to analyze the impact of socio-demographic and proximate determinants on the incidence of infant death at the age of 0-11 months in rural areas of Indonesia. This study emphasizes education level, wealth quintile, sex of the child, maternal smoking habits, and age at first birth to the incidence of infant mortality. This study also identifies the association between breastfeeding patterns, birth order, and birth weight as proximate determinants of the incidence of infant mortality, especially in rural Indonesia.

\section{Method}

\subsection{Data}

The data were obtained from 2017 Indonesian Demographic and Health Survey (IDHS). The 2017 IDHS sampling frame was prepared using the 2010 Population Census block (SP 2010) (BKKBN et al., 2018). The survey represents 1,970 census blocks in urban and rural areas with a sample of 49,250 households obtained by female 
respondents aged 15-49 years about 59,100 respondents (BKKBN et al., 2018). The sampling technique was applied in two stratified stages, the probability proportional to size (PPS) systematically selecting the size of the number of households stratified into urban and rural areas and sorted based on the wealth index of the 2010 Population Census (BKKBN et al., 2018). Systematic random selection was carried out on 25 households selected in the census block. Free downloadable data can be accessed by registering through the Demographic and Health Survey (DHS) website. This study used a questionnaire for women aged 15-49 years to collect information from women of childbearing age regarding the number of children born alive to a certain age, socio-demographic factors, and the closest determinant of the incidence of infant mortality.

\subsection{Inclusion and Exclusion Criteria}

The inclusion criteria of this study were: (1) women of childbearing age 15-49 years who are married or live together; (2) children born alive to 11 months; (3) babies who die between the ages of 0-11 months or before reaching their first birthday; and (4) age of fertile women living in rural areas. The exclusion criteria were infants living in urban areas. This study selected 43,787 infants as the initial sample. After that, the study excluded 78 infants who reported missing information on selected variables. Therefore, the final sample used in this study was 43,709 babies from villages in 34 provinces in Indonesia.

\subsection{Key Explanatory Variables}

The infant mortality rate is calculated based on the mother's statement in this case, whether the mother has successfully given birth and the baby survives until the age of 11 month. The birth order is classified into the third child or more, second child, and first child. Birth weight is classified as greater than or equal to 2500 grams and less than 2500 grams. Breastfeeding status is identified by whether the mother has breastfed her baby up to 11 months of age. The education status of the mothers is classified into secondary education or above, primary education, and no education at all. The wealth quintile variable is divided into rich, middle, and poor groups. The smoking habits of mothers were grouped into non-smoking mothers, mothers who smoked daily, and mothers who smoked infrequently. The age of mother at first delivery was categorized into less than 20 years, 20 to 39 years, and 40 to 49 years. The sex of an infant's variable consists of female and male infants.

The initial stage of the analysis was carried out using a descriptive approach through univariate analysis by describing the frequency distribution of the respondent characteristics of each variable. A stage is an inferential approach through bivariate and multivariate analysis. The bivariate analysis aims to explain the relationship between each predictor variable on the response variable, testing the relationship between the two variables with the chi-square test (El-Habil, 2012). The multivariate analysis aims to determine the effect of the overall predictor variable on the response variable. This influence is seen both simultaneously and partially through multiple logistic regression with $\mathrm{p}$-value $\leq 0.05$ so that there is an influence of predictor variables in this case socio-demographic factors and the lowest determinant on infant mortality variables. Also, risk factors were measured for predictor variables for the incidence of infant mortality using odds ratios (ORs) with $95 \%$ confidence intervals (CIs) (Kleinbaum \& Klein, 2010). Data analysis in this study was calculated using R-4.0.2 for Windows.

\subsection{Ethical Consideration}

This study does not contain private records or confidential information. All procedures and surveys for the 2017 IDHS have been reviewed and permitted by the ICF International Institutional Review Board (IRB). The survey procedures have been considered by the ICF IRB, the Indonesian Ministry of Health, and the Indonesia National Population and Family Planning Board for the protection of human subjects and in compliance with Indonesia's laws and norms.

\section{Results}

\subsection{Characteristics of Respondents}

Samples that met the requirements for data analysis were 43,709 infants in rural Indonesia in which 2,050 infants had been declared died before the age of 11 months and 41,659 infants who had survived until the age of 11 months. Table 1 revealed the frequency distribution of the respondent characteristics in this study. The results of the descriptive analysis showed that the proportion of first and second birth order was more than $40 \%$ compared to the third or more birth order (13.5\%). Only less than $1.3 \%$ of infants were born with low birth weight $(<2,500$ grams). The majority of mothers did not breastfeed their babies (83.0\%). About $50.1 \%$ of mothers had graduated from primary school education, $59.1 \%$ of mothers came from the poor level of wealth quintile, and more than $90.0 \%$ of mothers had a non-smoking habit. More than 50 percent of the mothers were delivered their first infants at the age of 20-39 years (53.0\%). The proportion of sex of infants born was nearly equal between females and males infants. 
Table 1. Characteristics of infant mortality (0-11 month), rural Indonesia, 2017 (N=43.709)

\begin{tabular}{|c|c|c|c|}
\hline Variable & & $\mathbf{N}$ & $\%$ \\
\hline \multirow[t]{2}{*}{ Infant mortality (0-11 month) } & No & 41,659 & 95.3 \\
\hline & Yes & 2,050 & 4.7 \\
\hline \multicolumn{4}{|l|}{ Proximate determinant factors } \\
\hline \multirow[t]{3}{*}{ a. Birth order } & Third or more & 5,907 & 13.5 \\
\hline & Second & 19,708 & 45.1 \\
\hline & First & 18,094 & 41.4 \\
\hline \multirow[t]{2}{*}{ b. Birth weight } & $\geq 2.500 \mathrm{gr}$ & 43,150 & 98.7 \\
\hline & $<2.500$ gr & 559 & 1.3 \\
\hline \multirow[t]{2}{*}{ c. Breastfeeding status } & Yes & 7,431 & 17.0 \\
\hline & No & 36,278 & 83.0 \\
\hline \multicolumn{4}{|l|}{ Socio-demographic factor } \\
\hline \multirow[t]{3}{*}{ a. Educational status of mother } & Secondary and above & 19,836 & 45.4 \\
\hline & Primary & 21,915 & 50.1 \\
\hline & No education & 1,958 & 4.5 \\
\hline \multirow[t]{3}{*}{ b. Wealth quintile } & Rich & 9,469 & 21.7 \\
\hline & Middle & 8,426 & 19.3 \\
\hline & Poor & 25,814 & 59.1 \\
\hline \multirow[t]{3}{*}{ c. Smoking habit of mother } & Not smoking & 42,439 & 97.1 \\
\hline & Daily & 511 & 1.2 \\
\hline & Infrequently & 759 & 1.7 \\
\hline \multirow[t]{3}{*}{ d. Age of mother at first delivery } & $<20$ year & 20,289 & 46.4 \\
\hline & 20-39 year & 23,396 & 53.5 \\
\hline & 40-49 year & 24 & 0.1 \\
\hline \multirow[t]{2}{*}{ e. Sex of infant } & Female & 21,183 & 48.5 \\
\hline & Male & 22,526 & 51.5 \\
\hline
\end{tabular}

Note: Author's calculation.

\subsection{The Result of Bivariate Analysis}

Table 2 shows the results of the bivariate analysis to determine the relationship between the incidence of infant mortality and the predictor variables, namely socio-demography and the proximate determinant. The statistical results of the chi-square test showed a significant relationship ( $p$-value $\leq 0.05)$ between the incidence of infant mortality and the proximate determinants, including birth order, and breastfeeding status of the infants. However, the infant's birth weight did not significantly relate $(p$-value $>0.05)$ to the incidence of infant mortality in rural Indonesia. Socio-demographic factors, namely the educational status of the mother, wealth quintile, smoking habit of the mother, age of mother at first delivery, and sex of the infant revealed a significant association ( $p$-value $\leq 0.05$ ) to the incidence of infant mortality in rural Indonesia. 
Table 2. Bivariate analysis between infant mortality (0-11 month) and proximate and socio-demographic factors, rural Indonesia, 2017

\begin{tabular}{|c|c|c|c|c|c|c|c|c|}
\hline \multirow{3}{*}{\multicolumn{2}{|c|}{ Variable }} & & \multicolumn{4}{|c|}{ Infant mortality } & \multirow{3}{*}{ Chi square } & \multirow{3}{*}{ p-value } \\
\hline & & & \multicolumn{2}{|l|}{ No } & \multicolumn{2}{|l|}{ Yes } & & \\
\hline & & & $\mathbf{N}$ & $\%$ & $\mathbf{n}$ & $\%$ & & \\
\hline \multicolumn{9}{|c|}{ Proximate determinant factor } \\
\hline \multirow{3}{*}{\multicolumn{2}{|c|}{ a. $\quad$ Birth order }} & Third or more & 5,564 & 13.4 & 342 & 16.7 & 42.5 & $0.00 * *$ \\
\hline & & Second & 18,919 & 45.4 & 790 & 38,5 & & \\
\hline & & First & 17,176 & 41.2 & 918 & 44.8 & & \\
\hline \multirow{2}{*}{\multicolumn{2}{|c|}{ b. Birth weight }} & $\geq 2.500$ grams & 41,133 & 98.7 & 2,018 & 98.4 & 1.36 & 0.24 \\
\hline & & $<2.500$ grams & 526 & 1.3 & 32 & 1.6 & & \\
\hline \multirow{2}{*}{\multicolumn{2}{|c|}{ c. Breastfeeding status }} & Yes & 7,230 & 17.4 & 201 & 9.8 & 78.8 & $0.00 * *$ \\
\hline & & No & 34,430 & 82.6 & 1,848 & 90.2 & & \\
\hline \multicolumn{9}{|c|}{ Socio-demography factor } \\
\hline \multirow{3}{*}{\multicolumn{2}{|c|}{$\begin{array}{ll}\text { a. } & \text { Educational status of mother }\end{array}$}} & Secondary and above & 19,158 & 46.0 & 678 & 33.1 & 204.3 & $0.00 * *$ \\
\hline & & Primary & 20,732 & 49.8 & 1,183 & 57.7 & & \\
\hline & & No education & 1,769 & 4.2 & 189 & 9.2 & & \\
\hline \multirow{3}{*}{\multicolumn{2}{|c|}{ b. Wealth quintile }} & Rich & 9,172 & 22.0 & 296 & 14.4 & 120.0 & $0.00 * *$ \\
\hline & & Middle & 8,119 & 19.5 & 308 & 15.0 & & \\
\hline & & Poor & 24.368 & 58.5 & 1,446 & 70.6 & & \\
\hline \multirow{3}{*}{\multicolumn{2}{|c|}{ c. Smoking habit of mothers }} & Not smoking & 40,474 & 97.1 & 1,965 & 95.8 & 16.7 & $0.00^{* *}$ \\
\hline & & Daily & 485 & 1.2 & 26 & 1.3 & & \\
\hline & & Infrequently & 700 & 1.7 & 59 & 2,9 & & \\
\hline \multirow{3}{*}{\multicolumn{2}{|c|}{ d. Age of mother at first delivery }} & 20-39 year & 22,524 & 54.1 & 871 & 42.5 & 117.5 & $0.00^{* *}$ \\
\hline & & $<20$ year & 19,116 & 45.9 & 1,174 & 57.3 & & \\
\hline & & $40-49$ year & 19 & 0.05 & 5 & 0.2 & & \\
\hline \multirow{2}{*}{\multicolumn{2}{|c|}{ e. Sex of infant }} & Female & 20,275 & 48.7 & 907 & 44.2 & 15.3 & $0.00^{* *}$ \\
\hline & & Male & 21,384 & 51.3 & 1,143 & 55.8 & & \\
\hline
\end{tabular}

Note. Author's calculation, IDHS $2017 ; *(\mathrm{p}$-value $\leq 0.1) ; * *(\mathrm{p}$-value $\leq 0.05)$.

\subsection{The Result of Logistic Regression Analysis}

Table 3 revealed the results of the final model of multiple logistic regression. The second (OR: $0.88 ; 95 \%$ CI: $0.78-1.01)$ or third (OR: $0.73 ; 95 \% \mathrm{CI})$ birth order: $(0.66-0.81)$ were more likely to have an incidence of infant mortality than the first birth order. The odds of infant mortality with low birth weight (LBW: $<2,500$ gram) was 1.59 times higher (95\% CI: 1.10-2.29) than normal birth weight ( $\geq 2,500$ gram). Infant mortality of a mother who did not breastfeed her child was 1.87 times (95\% CI: 1.61-2.18) relatively higher than those mothers who breastfeed their infants. Mothers who come from the poor wealth index have the highest chance of infant mortality, compared to mothers who came from middle and rich wealth index (OR: $1.58 ; 95 \%$ CI: 1.38-1.80). Infant mortality among uneducated mothers had the highest risk compared to educated mothers (OR: 2.23 ; $95 \%$ CI: 1.87-2.67). The possibilities of mothers who smoked daily was 1.44 times more likely (95\% CI: $1.09-1.88$ ) to cause infant mortality compared to a non-smoker mother. Those mothers who delivered their infants at the age of 40-49 years were more likely to be 6.10 times (95\% CI: $2.18-17.08$ ) of the incidence of infant mortality compared to those mothers who delivered their infants at the age of 20-39 years. The mothers who gave birth to their infants at the age below 20 years were 1.37 times higher odds (95\% CI: 1.24-1.50) of the incidence of infant mortality compared to those mothers who delivered their infants at the age of 20-39 years. Mothers who had male infants 
were 1.19 times more likely to experience infant mortality than mothers who had female infants.

Table 3. Multiple logistic regression model for determinants of infant mortality (0-11 month) in rural Indonesia, 2017

\begin{tabular}{|c|c|c|c|c|}
\hline Variable & & OR & $95 \% C I$ & p-value \\
\hline \multicolumn{5}{|l|}{ Proximate determinant factor } \\
\hline \multirow[t]{3}{*}{ a. Birth order } & First & Ref & & \\
\hline & Second & 0.88 & $0.78-1.01$ & $0.06^{*}$ \\
\hline & Third or more & 0.73 & $0.66-0.81$ & $0.00 * *$ \\
\hline \multirow[t]{2}{*}{ b. Birth weight } & $\geq 2.500$ grams & 1 & & \\
\hline & $<2.500$ grams & 1.59 & $1.10-2.29$ & $0.01 * *$ \\
\hline c. Breastfeeding status & Yes & 1 & & \\
\hline & No & 1.87 & $1.61-2.18$ & $0.00 * *$ \\
\hline \multicolumn{5}{|l|}{ Socio-demographyc factor } \\
\hline \multirow[t]{3}{*}{ a. Education of mother } & Secondary and above & Ref & & \\
\hline & Primary & 1.34 & $1.21-1.48$ & $0.00 * *$ \\
\hline & No education & 2.23 & $1.87-2.67$ & $0.00 * *$ \\
\hline \multirow[t]{3}{*}{ b. Wealth quintile } & Rich & Ref & & \\
\hline & Middle & 1.08 & $0.92-1.27$ & 0.35 \\
\hline & $\begin{array}{l}\text { Poor } \\
\text { Not smoking }\end{array}$ & $\begin{array}{l}1.58 \\
\operatorname{Ref}\end{array}$ & $1.38-1.80$ & $0.00 * *$ \\
\hline \multirow{2}{*}{ c. Smoking habit of mother } & Daily & 1.44 & $1.09-1.88$ & $0.01 * *$ \\
\hline & Infrequently & 0.79 & $0.53-1.18$ & 0.24 \\
\hline \multirow[t]{3}{*}{ d. Age of mother at delivery } & 20-39 year & Ref & & \\
\hline & $<20$ year & 1.37 & $1.24-1.50$ & $0.00 * *$ \\
\hline & $40-49$ year & 6.10 & $2.18-17.08$ & $0.00 * *$ \\
\hline \multirow[t]{2}{*}{ e. Sex of baby } & Female & Ref & & \\
\hline & Male & 1.19 & $1.09-1.31$ & $0.00 * *$ \\
\hline
\end{tabular}

Note. Author's calculation, IDHS 2017; *(p-value $\leq 0.1) ; * *(p-v a l u e ~ \leq 0.05)$.

\section{Discussion}

This study investigated the impact of socio-demographic and the proximate determinant factors on the incidence of infant mortality in rural Indonesia using data from the 2017 Indonesia Demographic and Health Survey. This research showed that the contribution of factors that influence the incidence of infant mortality still varied in rural areas in Indonesia. The results showed that birth order had a significant effect on the incidence of infant mortality (0-11 months). The higher birth order had a higher probability of the incidence of infant mortality ( $0-11$ months) (Ahrens et al., 2017; Mishra et al., 2018). The birth order of the first and last children is more likely to be at risk of infant mortality than middle birth order (Mishra et al., 2018; Mustafa, 2008). The first birth order had higher odds of infant mortality since the mothers had no experience taking care of their first child. Thus, the first child had a higher chance of dying from preventable injuries (Thoma et al., 2019). However, the last birth order with a high number of births can reduce the chances of survival of the baby because maternal fatigue decreases the mother's ability to concentrate (Iwata et al., 2018), which can increase the incidence of postpartum fatigue (Thomas \& Spieker, 2016), feeling tight Senol et al., 2019), and caused their babies to wean their breast milk earlier (Fata \& Atan, 2018).

The logistic regression model shows that there is a significant influence between low birth weight (LBW: $<2,500$ grams) on the risk of infant mortality in rural areas in Indonesia. Infants who experience low birth weight have a 
higher likelihood of infant mortality due to immaturity in humoral, multi-organ, and cellular immunity (Hughes et al., 2017). LBW is a determining factor that is closely related to the risk of infant mortality due to preterm birth or intrauterine growth retardation (Sovio et al., 2012). Other studies have shown that babies who are small at birth are more likely to experience infant mortality than babies with a standard size or larger (Dube et al., 2013; Khadka et al., 2015).

In rural areas in Indonesia, mothers who breastfeed their babies are more likely to reduce infant mortality than mothers who do not breastfeed. Previous research also showed that babies who have not been breastfed by their mothers have twice the risk compared to babies who are breastfed by their mothers (Sankar et al., 2015). The duration of breastfeeding in the first six months is one of the predictors of a significant reduction in infant mortality (Oktaria et al., 2017; Sankar et al., 2015). A study in South Africa showed that exclusive or partial breastfeeding reduces the risk of infant mortality (Motsa et al., 2016)

This study found that maternal education has a significant effect on infant mortality in rural Indonesia. Mothers with higher secondary education are more likely to experience infant survival than mothers with primary or uneducated education in rural Bangladesh (Akter et al., 2015). Increased maternal education leads to delays in age at first marriage, delays in the first delivery, and job opportunities for women (Kiross et al., 2019).

The wealth index, which is created by the resources owned by households, is very close to income (Ladusingh et al., 2016). Babies who have mothers with a low wealth index tend to have the highest risk of death compared to babies who have mothers from the middle to upper wealth index (Tall et al., 2018). Previous research has shown that the infant mortality rate is higher for mothers with poor and middle status compared to mothers with richer status (Khadka et al., 2015). Previous research from Ezeh et al. (2015) showed a significant effect of infant mortality in poor households, living in rural areas, and having uneducated mothers in Nigeria. Community-based interventions for mothers living in rural areas with low economic status are needed to increase the survival rate of children in rural Nigeria (Ezeh et al., 2015). Babies born to families with a higher wealth index and mothers with higher education tend to receive better nutrition, health care, and education to reduce the risk of infant mortality (Hosseinpoor et al., 2006).

This study also reveals a significant relationship between maternal smoking habits and the risk of infant mortality in rural Indonesia. The more often the mother smokes, the higher the likelihood of infant mortality (Cerda et al., 2017; Ratnasiri et al., 2020). Mothers who quit smoking reduce the risk of infant mortality (Johansson et al., 2009). Previous research found that there was an association between smoking, premature infant mortality, and sudden infant death syndrome (Dietz et al., 2010). Patrick et al. (2016) emphasized that there is a relationship between an increase in tax and cigarette prices with a decrease in infant mortality so that stakeholders can implement policies and strategies for increasing cigarette taxes in the context of preventing infant mortality.

Maternal age at first delivery is closely related to the incidence of infant mortality. It is shown by the logistic regression model that mothers at a young age (15-19 years) and the end of the reproductive period (40-49 years) are more likely to be at risk of experiencing infant death than those at first age. - when the mother is 20-39 years old. These results are in line with previous studies, where babies born to mothers aged 20-35 years have a 0.31 times lower risk of neonatal death than babies born to mothers aged less than 20 years and more than 35 years (Sari, 2016). It is also clear that delaying the age at first birth in women in their 20 s reduces infant mortality and improves infant health (Finlay et al., 2011). Mothers who have male babies are more likely to have a higher risk of infant mortality than female babies. It is in line with research in South Africa that revealed that female infants tend to have a lower risk of infant mortality than male babies (Motsa et al., 2016). Previous research has shown a higher relationship between infant mortality in males than in females (Sovio et al., 2012).

This study finding indicates the need to allocate more to girl's education and family planning. The increasing number of women studying in schools will encourage the increased age at marriage and subsequently increase the age at first delivery and reduce adolescent pregnancies. It would address the teenage pregnancy issue and reduce the risk of infant mortality.

This study is limited to the number of variables that show a statistically significant relationship with the incidence of infant mortality in rural areas in Indonesia. In general, cross-sectional studies find it arduous to identify causality because exposure, as well as the measured results, collected at the same time, thus, can create a memory bias.

\section{Conclusion}

In conclusion, infant mortality is a vital indicator of community health and general development of a nation, since it reveals the social, economic, and environmental circumstances in which infants and their communities live, 
including their health systems. The study indicates evidence of disparities in the reasons for infant mortality among divergent socio-demographic subclasses. Yet, in the face of dwindling infant mortality in rural areas of Indonesia, there is a vital prerequisite to classify that only the most significant determinants that affect infant mortality. Decrease in infant mortality rate in the proximate determinant factor was associated with normal birth weight, breastfeeding, number, and spacing of controlled and planned births. In this regard, the socio-demographic factors that can reduce infant mortality are associated with factors such as higher education, better economic status, the ideal age at first birth (not too young or too old), smoking habits, especially during pregnancy. Another factor is maintaining the health of the baby during the prenatal and postnatal periods, especially male babies who are more prone to death than female babies.

\section{Acknowledgements}

The authors would like to acknowledge the support of the Badan Kependudukan dan Keluarga Berencana Nasional.

\section{Authors' Contributions}

DKI: Conceptualized the design and overall study. She analyzed, interpreted the data, and prepared the manuscript. IE: Supported in statistical analyses, interpretation of data, and reviewed the manuscript, and provided inputs. EP: Critically reviewed the manuscript and provided inputs. All authors read and approved the final manuscript.

\section{Ethics Approval}

This study involves the analysis of anonymous publicly available secondary data and therefore no ethical approval was required.

\section{Data Availability Statement}

Data are available in a public, open access repository.

\section{Competing Interests Statement}

The authors declare that there are no competing or potential conflicts of interest.

\section{References}

Adewuyi, E. O., Zhao, Y., \& Lamichhane, R. (2017). Risk factors for infant mortality in rural and urban Nigeria: Evidence from the national household survey. Scand $J$ Public Health, 45(5), 543-554. https://doi.org/10.1177/1403494817696599

Ahrens, K. A., Rossen, L. M., Thoma, M. E., Warner, M., \& Simon, A. E. (2017). Birth order and injury-related infant mortality in the U.S. Am J Prev Med., 53(4), 412-420. https://doi.org/10.1016/j.physbeh.2017.03.040

Ajaero, C., \& Owoh, O. (2013). The pattern and determinants of infant mortality in rural Nigeria. Innovare Journal of Social Sciences, 1(1). Retrieved from http://innovareacademics.in/journals/index.php/ijss/article/view/339

Akter, T., Hoque, D. M., Chowdhury, E. K., Rahman, M., Russell, M., \& Arifeen, S. E. (2015). Is there any association between parental education and child mortality? A study in a rural area of Bangladesh. Public Health, 129(12), 1602-9. https://doi.org/10.1016/j.puhe.2015.08.004

Banerjee, S. (2018). Major determinants of infant mortality: District-level evidences from Odisha. Journal of Health Management, 20(3), 345-362. https://doi.org/10.1177/0972063418779912

Badan Kependudukan dan Keluarga Berencana Nasional (BKKBN), Badan Pusat Statistik (BPS), Kementerian Kesehatan RI, \& USAID. (2018). Indonesia Demographic and Health Survey 2017. Jakarta: BKKBN, BPS, Kementerian Kesehatan RI dan USAID.

Boghossian, N. S., Geraci, M., Edwards, E. M. \& Horbar, J. D. (2018). Sex differences in mortality and morbidity of infants born at less than 30 weeks' gestation. Pediatrics, 142(6), e20182352.

Byberg, S., Østergaard, M. D., Rodrigues, A., Martins, C., Benn, C. S., Aaby, P., \& Fisker, A. B. (2017). Analysis of risk factors for infant mortality in the 1992-3 and 2002-3 birth cohorts in rural Guinea-Bissau. PLOS One, 12(5), e0177984.

Carolan, M., \& Frankowska, D. (2011). Advanced maternal age and adverse perinatal outcome: a review of the evidence. Midwifery, 27(6), 793-801. https://doi.org/10.1016/j.midw.2010.07.006

Central Bureau of Statistics (BPS), National Family Planning Coordinating Board, Ministry of Health, The Demographic and Health Surveys Program, \& Macro International. (1991). Indonesia Demographic and Health Survey 1991. Jakarta: National Family Planning Coordinating Board. 
Cerda, J., Bambs, C., \& Vera, C. (2017). Infant morbidity and mortality attributable to prenatal smoking in Chile. Rev Panam Salud Publica, 41(e106). https://doi.org/10.26633/RPSP.2017.106

Chen, A., Oster, E., \& Williams, H. (2016). Why is infant mortality higher in the United States than in Europe? American Economic Journal: Economic Policy, 8(2), 89-124. https://doi.org/10.1257/pol.20140224

Christian, P., Mullany, L. C., Hurley, K. M., Katz, J., \& Black, R. E. (2015). Nutrition and maternal,neonatal,and child health. Seminars in Perinatology, 1-12. https://doi.org/10.1053/j.semperi.2015.06.009

Dietz, P. M., England, L. J., Shapiro-Mendoza, C. K., Tong, V. T., Farr, S. L., \& Callaghan, W. M. (2010). Infant morbidity and mortality attributable to prenatal smoking in the U.S. American Journal of Preventive Medicine, 39(1), 45-52.

Ding, G., Yu, J., Chen, Y., Vinturache, A., Pang, Y., \& Zhang, J. (2017). Maternal smoking during pregnancy and necrotizing enterocolitis-associated infant mortality in preterm babies. Sci Rep, 31(7), 45784-45796.

Dube, L., Taha, M., \& Asefa, H. (2013). Determinants of infant mortality in community of Gilgel Gibe Field Research Center, Southwest Ethiopia: A matched case control study. BMC Public Health, 13(1). https://doi.org/10.1186/1471-2458-13-401

El-Habil, A. M. (2012). An application on multinomial logistic regression model. Pakistan Journal of Statistics and Operation Research, 8(2), 271-291. https://doi.org/10.18187/pjsor.v8i2.234

Ely, D. M., Driscoll, A. K., \& Matthews, T. J. (2017). Infant mortality rates in rural and urban areas in the United States. Infant Mortality Rates in Rural and Urban Areas in the United States, Sep(285), 1-8.

Everard, M. L. (2016). Paediatric respiratory infections. Eur Respir Rev., 25(139), 36-40. https://doi.org/10.1183/16000617.0084-2015

Fata, S., \& Atan, S.U. (2018). The relationship between fatigue and breastfeeding self-efficacy. Niger J Clin Pract., 21(11), 1408-1414. https://doi.org/10.4103/njcp.njcp_366_17

Hotz, V.J. \& Pantano, J. (2015). Strategic parenting, birth order and school performance. Journal of Population Economics, 28, 911-936. https://doi.org/10.1007/s00148-015-0542-3

Hughes, M. M., Black, R. E., \& Katz, J. (2017). 2500-g low birth weight cutoff: History and implications for future research and policy. Matern Child Health J., 21(2), 283-289. https://doi.org/10.1007/s10995-016-2131-9

Humphrey, L., Bello, S., \& Rousham, E. (2012). Sex differences in infant mortality in spitalfields, London, 1750-1839. Journal of Biosocial Science, 44(1), 95-119. https://doi.org/10.1017/S0021932011000484

Hosseinpoor AR, Van Doorslaer E, Speybroeck N, Naghavi M, Mohammad K, Majdzadeh R, Delavar B, Jamshidi H, Vega J. Decomposing socioeconomic inequality in infant mortality in Iran. Int J Epidemiol., 35(5), $1211-9$. https://doi.org/10.1093/ije/dyl164

Iwata, H., Mori, E., Sakajo, A., Aoki, K., Maehara, K., \& Tamakoshi, K. (2018). Course of maternal fatigue and its associated factors during the first 6 months postpartum: a prospective cohort study. Nurs Open, 5(2), 186-196. https://doi.org/10.1002/nop2.130

Johansson, A.L., Dickman, P.W., Kramer, M.S., \& Cnattingius, S. (2009). Maternal smoking and infant mortality: does quitting smoking reduce the risk of infant death? Epidemiology, 20(4), 590-7. https://doi.org/10.1097/EDE.0b013e31819dcc6a

Khadka, K. B., Lieberman, L. S., Giedraitis, V., Bhatta, L., \& Pandey, G. (2015). The socio-economic determinants of infant mortality in Nepal: Analysis of Nepal Demographic Health Survey, 2011. BMC Pediatrics, 15(1), 1-11. https://doi.org/10.1186/s12887-015-0468-7

Kiross, G. T., Chojenta, C., Barker, D., Tiruye, T. Y., \& Loxton, D. (2019). The effect of maternal education on infant mortality in Ethiopia: A systematic review and meta-analysis. PLOS One, 14(7), e0220076. https://doi.org/10.1371/journal.pone.0220076

Kleinbaum, D. G., \& Klein, M. (2010). Logistic regression: A self-learning text (Springer). London: Springer. https://doi.org/10.1007/978-1-4419-1742-3

Kozuki, N., Lee, A. C. C., Silveira, M. F., Sania, A., Vogel, J. P., Adair, L., ... \& Child Health Epidemiology Reference Group Small-for-Gestational-Age-Preterm Birth Working Group (2013). The associations of parity and maternal age with small-for-gestational-age, preterm, and neonatal and infant mortality: A meta-analysis. BMC Public Health, 13(SUPPL.3). https://doi.org/10.1186/1471-2458-13-S3-S2 
Kramer, K., \& Lancaster, J. (2010). Teen motherhood in cross-cultural perspective. Annals of Human Biology, 37(5), 613-628.

Kumar, A., \& Singh, A. (2014). Is economic inequality in infant mortality higher in urban than in rural India? Maternal Child Health J., 18(9), 2061-2070. https://doi.org/10.1007/s10995-014-1452-9

Kynast-Wolf, G., Schoeps, A., Winkler, V., Stieglbauer, G., Zabré, P., Müller, O., Sie, A. \& Becher, H. (2019). Clustering of infant mortality within families in rural Burkina Faso. Am J Trop Med Hyg, 100(1), 187-191.

Ladusingh, L., Gupta, A. K., \& Yadav, A. (2016). Ecological context of infant mortality in high-focus states of India. Epidemiol Health, 38, e2016006..

Liang, F. W., Chou, H. C., Chiou, S. T., Chen, L. H., Wu, M. H., Lue, H. C., .. \& Lu, T. H. (2018). Trends in birth weight-specific and adjusted infant mortality rates in Taiwan between 2004 and 2011. Pediatr Neonatol, 59(3), 267-273. https://doi.org/10.1016/j.pedneo.2017.08.013

Mishra, S. K., Ram, B., Singh, A., \& Yadav, A. (2018). Birth order, stage of infancy and infant mortality in India. Journal of Biosocial Science, 50(5), 604-625. https://doi.org/10.1017/S0021932017000487

Modin, B. (2002). Birth order and mortality: a life-long follow-up of 14,200 boys and girls born in early 20 th century Sweden. Soc Sci Med., 54(7), 1051-1064. https://doi.org/10.1016/s0277-9536(01)00080-6

Mohamoud, Y. A., Kirby, R. S., \& Ehrenthal, D. B. (2019). Poverty, urban-rural classification and term infant mortality: a population-based multilevel analysis. BMC Pregnancy Childbirth, 19(40). https://doi.org/10.1186/s12884-019-2190-1

Motsa, L. F., Ibisomi, L., \& Odimegwu, C. (2016). The influence of infant feeding practices on infant mortality in Southern Africa. Matern Child Health J, 20(10), 2130-2141. https://doi.org/10.1007/s10995-016-2033-x

Muj, K. A., \& Bharadwaj, P. (2015). Maternal education and child mortality in Zimbabwe. J Health Econ, 44(1), 97-117. https://doi.org/10.1016/j.jhealeco.2015.08.003

Mustafa, H. E. (2008). Socioeconomic determinants of infant mortality in Kenya. Humanities and Social Sciences, 2(2), $1-16 . \quad$ Retrieved from http://hdl.handle.net/10539/5805\%5Cnhttp://wiredspace.wits.ac.za/handle/10539/5805

Natarajan, G., Shankaran, S., Nolen, T. L., Sridhar, A., Kennedy, K. A., Hintz, S. R., ... \& Higgins, R.D. (2019). Neurodevelopmental outcomes of preterm infants with retinopathy of prematurity by treatment. Pediatrics. 144(2), e20183537. https://doi.org/10.1542/peds.2018-3537

Oktaria, V., Lee, K. J., Bines, J. E., Watts, E., Satria, C. D., Atthobari, J., .. \& Danchin, M. H. (2017). Nutritional status, exclusive breastfeeding and management of acute respiratory illness and diarrhea in the first 6 months of life in infants from two regions of Indonesia. BMC Pediatrics, 17. https://doi.org/10.1186/s12887-017-0966-X

Patrick, S. W., Warner, K. E., Pordes, E., \& Davis, M. M. (2016). Cigarette tax increase and infant mortality. Pediatrics, 137(1). https://doi.org/10.1542/peds.2015-2901

Ratnasiri, A. W. G., Lakshminrusimha, S., Dieckmann, R. A., Lee, H. C., Gould, J. B., Parry, S. S., Arief, V.N., DeLacy, I.H., DiLibero, R.J., \& Basford, K.E. (2020). Maternal and infant predictors of infant mortality in California, 2007-2015. PloS One, 15(8), e0236877. https://doi.org/10.1371/journal.pone.0236877

Riordan, D. V., Hattie, C. M. J., \& Stark, C. (2011). Family size and perinatal circumstances, as mental health risk factors in a Scottish birth cohort. Social Psychiatry and Psychiatric Epidemiology, 47, 975e983.

Roy, S., \& Haque, A. (2018). Effect of antenatal care and social well-being on early neonatal mortality in Bangladesh. BMC Pregnancy Childbirth, 18(1), 485-496. https://doi.org/10.1186/s12884-018-2129-y

Sankar, M. J., Sinha, B., Chowdhury, R., Bhandari, N., Taneja, S., Martines, J., \& Bahl, R. (2015). Optimal breastfeeding practices and infant and child mortality: A systematic review and meta-analysis. Acta Paediatrica, International Journal of Paediatrics, 104(November), 3-13. https://doi.org/10.1111/apa.13147

Santos, S., Santos, L., Campelo, V., \& Silva, A. (2016). Factors associated with infant mortality in a Northeastern Brazilian capital. Revista Brasileira de Ginecologia e Obstetricia / RBGO Gynecology and Obstetrics, 38(10), 482-491. https://doi.org/10.1055/s-0036-1584686

Sari, I. P. (2016). The determinants of infant mortality in neonatal period. Jurnal Kesehatan Masyarakat, 12(1), 139-149. https://doi.org/10.15294/kemas.v12i1.4882 
Senol, D. K., Yurdakul, M., \& Ozkan, S. A. (2019). The effect of maternal fatigue on breastfeeding. Niger J Clin Pract., 22(12), 1662-1668. https://doi.org/10.4103/njcp.njcp_576_18

Shahid, A. S. M. S. B., Ahmed, T., Kabir, S., Huq, K. A. T. M. E., Shahunja, K. M., Faruque, A. S. G., ... \& Chisti, M. J. (2019). Consequences of lack of neonatal breastfeeding in infants hospitalized for diarrhea at an urban hospital, Bangladesh: A case control design. Glob Pediatr Health, 6, 2333794X19851431. https://doi.org/10.1177/2333794X19851431

Sovio, U., Dibden, A., \& Koupil, I. (2012). Social determinants of infant mortality in a historical Swedish cohort. Paediatric and Perinatal Epidemiology, 26(5), 408-420. https://doi.org/10.1111/j.1365-3016.2012.01302.x

Tall, A. B., Faye, A., Ndiaye, A. A., Gaye, A., Gueye, B., Ngo, N. F., ... \& Tal-Dia, A. (2018). Community-based maternal and neonatal health services in Kolda and Sedhiou Districts of Senegal. Global Journal of Health Science, 10(3), 90-110. https://doi.org/10.5539/gjhs.v10n3p90

Thoma, M. E., Rossen, L. M., De Silva, D. A., Warner, M., Simon, A. E., Moskosky, S., \& Ahrens, K. A. (2019). Beyond birth outcomes: Interpregnancy interval and injury-related infant mortality. Paediatr Perinat Epidemiol. 33(5):360-370. https://doi.org/10.1111/ppe.12575

Thomas, K.A., \& Spieker, S. (2016). Sleep, depression, and fatigue in late postpartum. MCN Am J Matern Child Nurs., 41(2), 104-9. https://doi.org/10.1097/NMC.0000000000000213

Travers, C. P., Carlo, W. A., McDonald, S. A., Das, A., Bell, E. F., Ambalavanan, N., ... \& Eunice Kennedy Shriver National Institute of Child Health and Human Development Neonatal Research Network. (2018). Mortality and pulmonary outcomes of extremely preterm infants exposed to antenatal corticosteroids. $\mathrm{Am} \mathrm{J}$ Obstet Gynecol., 218(1), 130.e1-130.e13. https://doi.org/10.1016/j.ajog.2017.11.554

United Nations. (2017). The Sustainable Development Goals Report. United Nations. https://doi.org/10.18356/3405d09f-en

Vilanova, C. S., Hirakata, V. N., Buriol, V. C. de S., Nunes, M., Goldani, M. Z., \& Silvata, C. H. (2019). The relationship between the different low birth weight strata of newborns with infant mortality and the influence of the main health determinants in the extreme south of Brazil. Popul Health Metr, 17(15), 1-12. https://doi.org/10.1186/s12963-019-0195-7

Weldearegawi, B., Melaku, Y. A., Abera, S. F., Ashebir, Y., Haile, F., Mulugeta, A., Eshetu, F., \& Spigt, M. (2015). Infant mortality and causes of infant deaths in rural Ethiopia: A population-based cohort of 3684 births. BMC Public Health, 15(1), 770. https://doi.org/10.1371/journal.pone.0093099

World Health Organization (WHO). (2018). SDG 3: Ensure healthy lives and promote wellbeing for all at all ages. Retrieved from https://sdgcompass.org/sdgs/sdg-3/

\section{Copyrights}

Copyright for this article is retained by the author(s), with first publication rights granted to the journal.

This is an open-access article distributed under the terms and conditions of the Creative Commons Attribution license (http://creativecommons.org/licenses/by/4.0/). 